\title{
As normatividades sociais: suas conceituações aplicadas ao objeto cultural Jogo da Vida
}

\section{Social normativities: their concepts applied to the cultural object Jogo da Vida}

Pedro Matheus ${ }^{[1]}$, Ana Paula Cruz Penkala Dias (orientadora) ${ }^{[2]}$

\begin{abstract}
Resumo: Este artigo está vinculado com uma pesquisa maior, o Trabalho de Conclusão de Curso "A vida sem transgressões: o Jogo da Vida como objeto cultural e a sua propagação de normatividades sociais", e tem como intuito se aprofundar nos conceitos das normatividades sociais aplicadas ao objeto cultural Jogo da Vida, em sua edição de 2015 pela empresa Estrela. Metodologicamente, o artigo é uma pesquisa qualitativa de caráter exploratório, com natureza bibliográfica voltada aos Estudos Culturais. Os resultados obtidos auxiliam no entendimento sobre o conceito que anteriormente foi considerado uma premissa no início da pesquisa maior e ajudam nos processos conceituais da produção de um redesign do Jogo da Vida.
\end{abstract}

Palavras-chave: Jogo da Vida. Normatividades sociais. Objeto de cultura. Design. Estudos Culturais.

Abstract: This article is linked to a larger research, the Course Conclusion Work "Life without transgressions: the Game of Life as a cultural object and its propagation of social norms", and aims to deepen in the concepts of social norms applied to the cultural object Game Of Life, in its 2015 edition by the company Estrela. Methodologically, the

[1] Graduado em Design Gráfico, UFPEL.pedro.m.theus@gmail.com

[2] Doutora em Comunicação e Informação, UFRGS.penkala@gmail.com 
article is a qualitative research with an exploratory character, with a bibliographic nature focused on Cultural Studies. The results obtained help to understand the concept that was previously considered a premise at the beginning of the larger research and help in the conceptual processes of producing a redesign of the Game of Life.

Keywords: Game of Life. Social norms. Cultural object. Design. Cultural Studies.

\section{INTRODUÇÃo}

Este artigo visa apresentar resultados ligados com uma investigação maior, inserida no Trabalho de Conclusão de Curso intitulado "A vida sem transgressões: o Jogo da Vida como objeto cultural e a sua propagação de normatividades sociais". Nessa pesquisa, visa-se compreender o quadro de valores sociais passados pelo jogo de tabuleiro Jogo da Vida, brinquedo da empresa Estrela, em sua edição do ano de 2015. O objeto de estudo estreou em 1980 como uma adaptação brasileira ao jogo Game of Life, lançado nos Estados Unidos pela empresa Milton Bradley Company em 1960 (LEPORE, 2007). Tanto na versão nacional, quanto na internacional, o objetivo do jogo é claro: ser um vencedor na vida.

Percebe-se, em primeiras análises, o uso de estereótipos com o objetivo de indicar o caminho mais adequado a se seguir em vida para se ter sucesso e prestígio; favorecendo pessoas privilegiadas no contexto brasileiro e, consequentemente, invalidando minorias sociais ao excluir suas vivências e culturas da história do jogo. Enaltece e considera como vivência realmente válida aquela exercida por um homem branco, heterossexual, com o corpo "definido" e inserido em um contexto de felicidade capitalista que, em muitos casos, é reforçado pelas mídias, conservando um quadro de valores em prol daqueles que já detêm algum tipo de poder.

Frente a este discurso, que o jogo constrói de várias formas, foram geradas problematizações sobre sua estética, mecânica e narrativa em torno de questões de gênero, sexualidade, etnia, hegemonia norte-americana, discurso judaico-cristão e a falsa sensação de liberdade em vida. Para a realização desse processo de análise ser desenvolvido com êxito, 
foi necessário tomar como premissa, ou seja, como raciocínio inicial, a existência de normatividades sociais - conceito que será abordado adiante - no objeto de investigação.

Levando em consideração o exposto, a presente discussão tem como objetivo entender os conceitos em torno das normatividades sociais presentes no objeto cultural Jogo da Vida, juntamente com os seus efeitos em sociedade. Explorar mais a fundo o que antes foi considerado como premissa é a justificava que norteia o anseio de compreender os significados da normatividade e as conexões com outros pensamentos. A pesquisa é qualitativa, de caráter exploratório, tendo natureza bibliográfica com uma fundamentação teórica concentrada nos Estudos Culturais e apresenta, a seguir, considerações acerca do que esta exploração do objeto cultural Jogo da Vida dá a ver ao considerarmos as normatividades citadas e como elas são tratadas no jogo.

\section{SOBRE 0 JOGO DA VIDA}

Introduzido nos Estados Unidos em 1960, o Game of Life foi desenvolvido pelo designer de jogos e brinquedos Reuben Klamer para a Milton Bradley Company. O jogo foi produzido como comemoração ao centenário de The Checkered Game of Life, criado no ano de 1860 pelo litógrafo Milton Bradley, que trazia a jornada de vida de uma pessoa desde a infância até a "boa velhice", com abordagem de questões morais da época e passando por situações como pobreza, ruína e até o suicídio (THE GAME, 2006). Essas ações foram adaptadas por Klamer ao contexto histórico da Guerra Fria, no qual a necessidade de afirmar o American Way of Life concentrava destaque. Assim, a busca de felicidade e as discussões a respeito de vícios e virtudes se transformam, unicamente, na obtenção de bens e no acúmulo de dinheiro como principal objetivo da vida transmitido pelo jogo de tabuleiro (LEPORE, 2007).

Dessa forma, estes preceitos capitalistas também foram aplicados no lançamento da adaptação brasileira em 1980 pela empresa Estrela, o Jogo da Vida (VANZELLA, 2009). Seu 
percurso narrativo pretende simular a vivência real de uma pessoa desde sua adolescência até atingir uma idade avançada. Ao percorrer todo o caminho do tabuleiro, torna-se vencedor aquele que ao final do jogo obtiver mais dinheiro, seja se tornando milionário ou arriscando todos os seus bens para tornar-se magnata. Mesmo que se tratando de um produto envolto em um universo imaginário e aparentemente inofensivo, o que está em discussão sobre o Jogo da Vida é o seu caráter informacional, sendo utilizada para análise sua versão do ano de 2015 (Fig. 1, 2 e 3).

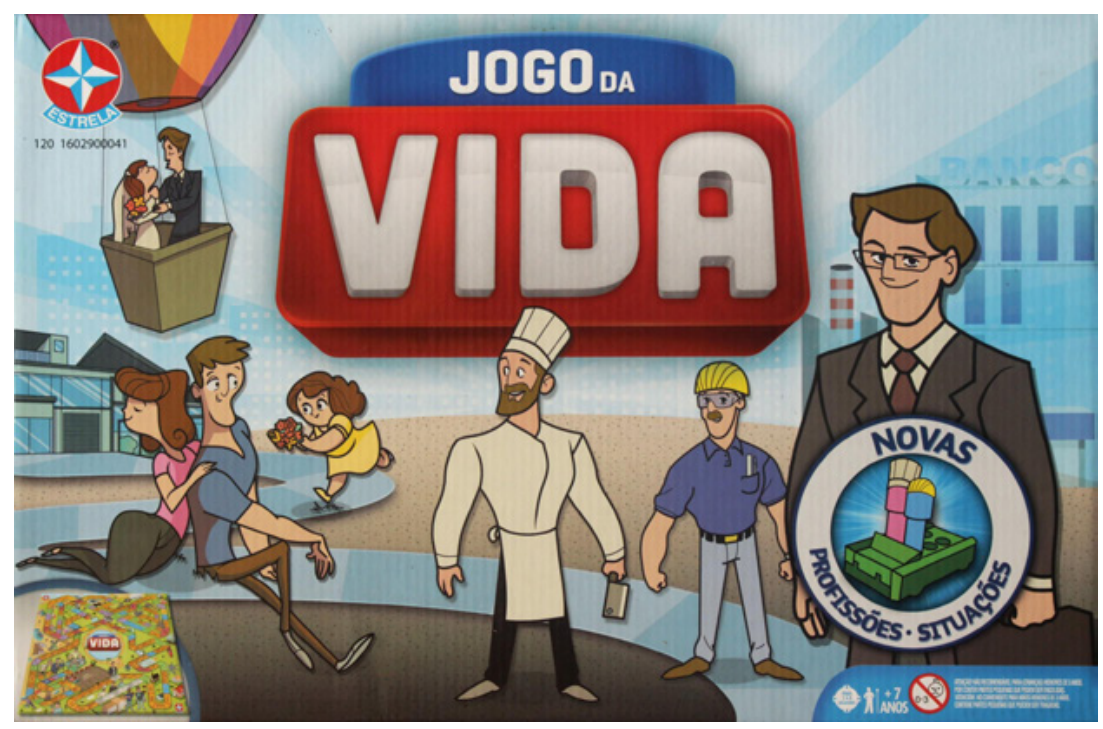

Figura 1 - Embalagem da versão de 2015 do Jogo da Vida. Fonte: Acervo do autor.

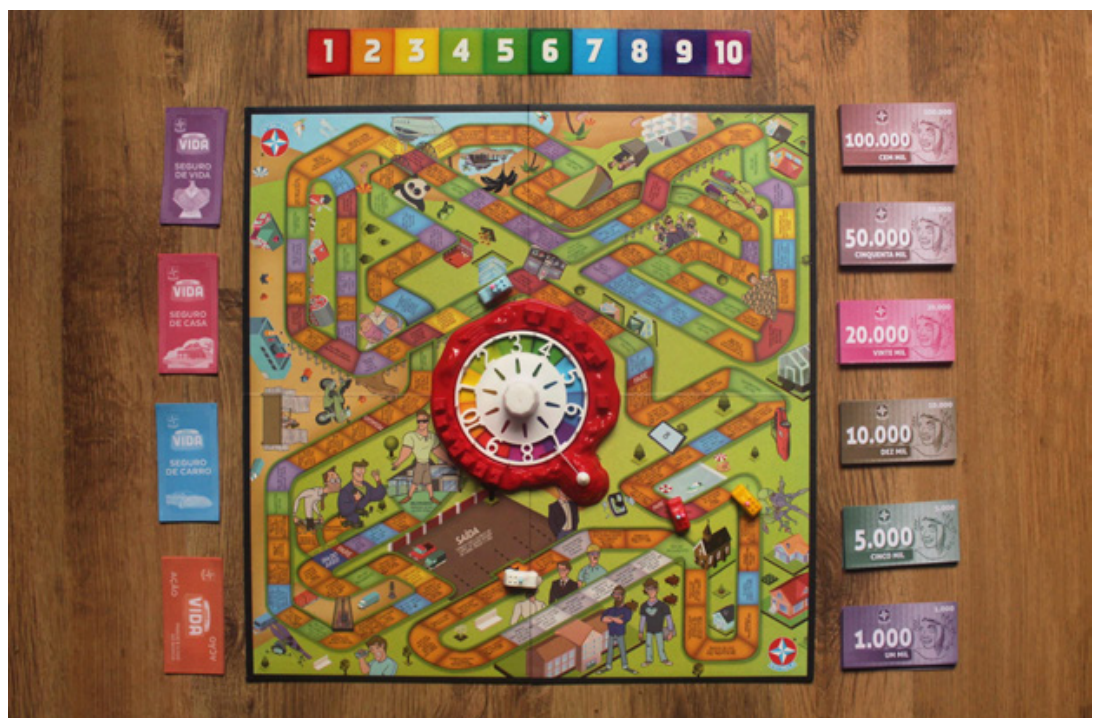

Figura 2 - Elementos gráficos da versão de 2015 do Jogo da Vida. Fonte: Acervo do autor. 


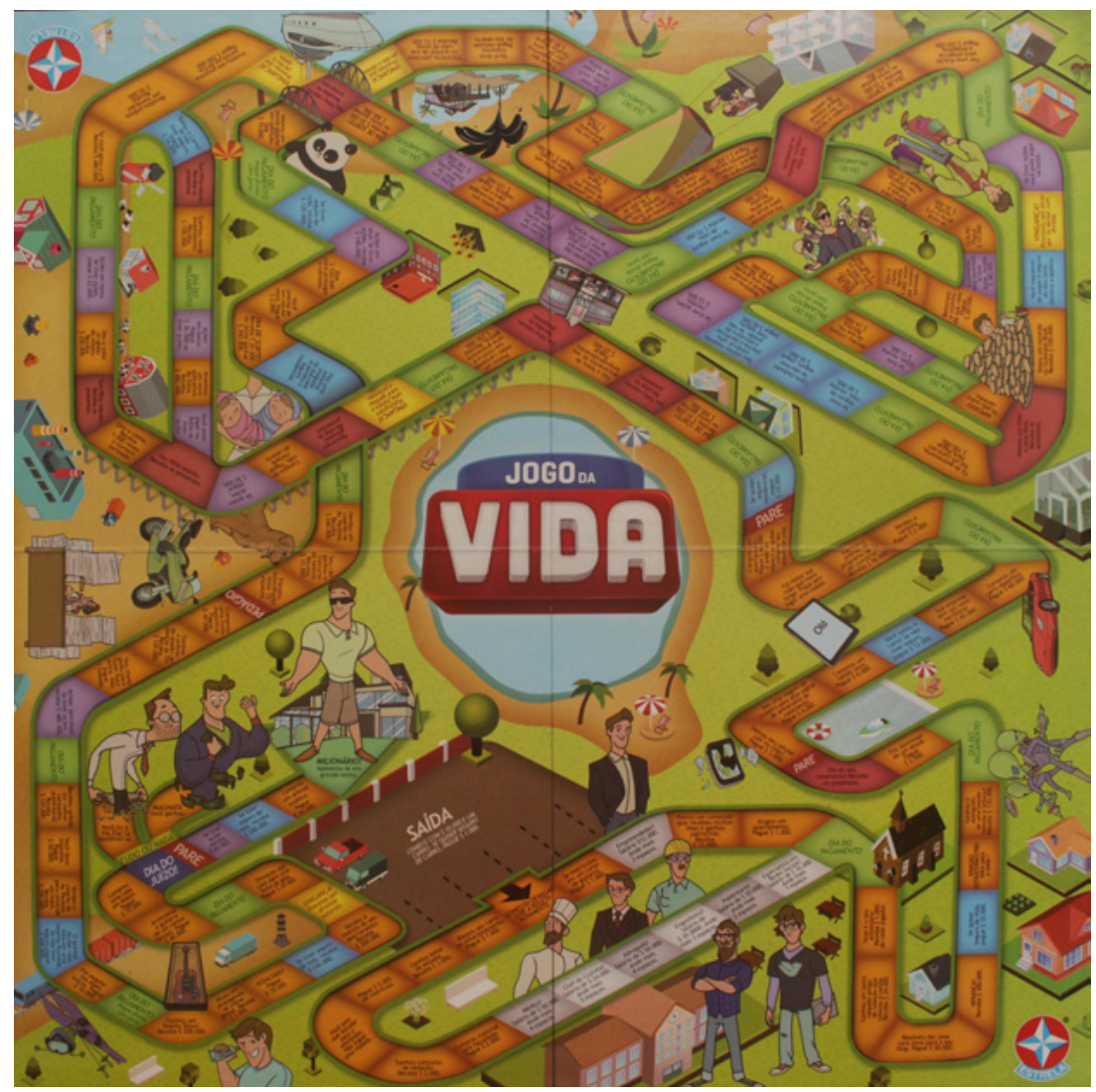

Figura 3 - Tabuleiro da versão de 2015 do Jogo da Vida. Fonte: Acervo do autor.

\section{SOBRE AS NORMATIVIDADES SOCIAIS}

Primeiramente, é necessário considerar e analisar o Jogo da Vida não em uma perspectiva comum de um brinquedo qualquer do mercado de jogos brasileiros, mas sim enquanto um objeto de cultura de mídia, já que, como afirma Kellner (2001, p.307):

(C A cultura da mídia põe à disposição imagens e figuras com as quais seu público possa identificar-se, imitando-as. Portanto, ela exerce importantes efeitos socializantes e culturais por meio de seus modelos de papéis, sexo e por meio das várias 'posições de sujeito' que valorizam certas formas de comportamento e modo de ser enquanto desvalorizam [â€! ] outros tipos.

Os objetos dessa cultura material refletem o processo histórico nos quais cada um está situado, dependendo do 
seu contexto e espaço de produção (LIMA, 2011). No caso do Jogo da Vida, há em sua narrativa, mecânica e estética o resultado da produção de estruturas que visam moldar determinados pensamentos. Essas estruturas serão referidas como normatividades sociais.

Por normatividades, neste estudo, compreende-se o conjunto de imposições sociais da cultura que lapidam e direcionam um estilo de conduta. As normatividades abordadas aqui atuam como ações sociais, individuais e institucionais que reforçam ou privilegiam padrões de pensar e agir; elas visam articular nossas noções, estabelecendo uma naturalização dos modelos sociais impostos (SEFFNER, 2013). Essas normas regulatórias exigem uma constante reafirmação dos sujeitos e decidem quem é aprovado ou rejeitado como um indivíduo de sucesso e de relevância em sociedade. Tais normatividades expressas atuam no patamar do que Pierre Bourdieu (1989) classifica como o poder simbólico.

O poder simbólico é um poder invisível, porém com capacidade de produzir efeitos reais que geram uma hierarquização entre aqueles que detêm ou não esse instrumento. Ele tem efeito "de fazer ver e fazer crer, de confirmar ou de transformar a visão do mundo" (BOURDIEU, 1989, p.14). O poder simbólico faz com que certas pessoas ou instituições possam persuadir as demais, atribuindo autoridade e crença à sua legitimidade. Quando já existem estruturas e discursos dominantes em uma sociedade, como as normatividades, esse sistema simbólico ajuda a naturalizar o que já está estabelecido, produzindo assim um consenso sobre os sentidos no mundo. Dentre essas estruturas apontadas por Bourdieu, a arte também é um poder simbólico e que abre espaço para considerar o Jogo da Vida como um instrumento de poder, uma vez que, como conceituam teóricos como Greg Costikyan, o jogo é arte e uma forma de cultura em seus elementos constituintes (SALEN; ZIMMERMAN, 2012).

As aqui chamadas normatividades podem ser situadas também permeando os conceitos de teóricos que vincu- 
lam sua produção com os estudos culturais. Inicialmente, tentando relacionar com os conceitos centrais abordados por Pierre Bourdieu, é possível conectar as normatividades através das análises do autor de como os indivíduos incorporam a estrutura social existente, abordando suas denominações de habitus e campo.

O habitus é o sistema de disposições socialmente construídas que afetam subjetivamente as atitudes; é a forma que os indivíduos compreendem e fazem a leitura do mundo, juntamente com suas práticas sociais. Já os campos, são redes de relações sociais que produzem algum tipo de hierarquização entre aqueles que estão presentes. Cada campo tem interesses e objetos de disputa específicos com influência de um determinado habitus. Nele, seus agentes ocupam posições que determinam quais as ações que provavelmente tomarão dentro desse campo (BOURDIEU, 1983). Nas palavras do autor, os campos são:

Espaços estruturados de posições (ou de postos) cujas propriedades dependem das posições nestes espaços, podendo ser analisadas independente das características de seus ocupantes (em parte determinadas por elas) (BOURDIEU, 1983, p.89).

Dentro da lógica de Bourdieu, as normatividades aparecem afetando o habitus por pertencerem às estruturas que direcionam esse conceito, influenciando diretamente os agentes do campo. Quanto mais um indivíduo obedece às normatividades sociais de um campo, maiores são as possibilidades dele ter um acúmulo de forças, constituindo seu capital.

Essas questões permitem um diálogo com o pensamento foucaultiano, que se dispõe a "cavar" os processos que produzem algo como discurso, ou seja, desvendar as construções de sentido no processo de algo de tornar-se uma verdade socialmente aceita. Nesse efeito de verdade, há um caminho de naturalização e aceitação de determinado discurso juntamente com sua cristalização. A cristalização, por sua vez, faz 
com que determinado discurso governe a verdade em uma espécie de regime, intensificando acordos sociais e posições de poder sobre determinadas coisas (FOUCAULT, 1996). É possível entender que o Jogo da Vida carrega um discurso e as normatividades sociais nele presentes fazem um efeito de verdade com seu mecanismo de poder simbólico sobre as mensagens passadas no tabuleiro. O Jogo da Vida também opera como um instrumento que instiga o desejo de seguir a verdade estabelecida; por meio de um imaginário de sucesso social, as pessoas compreendem que quanto mais de acordo com as normatividades estiverem, maiores serão suas facilidades em vida por terem privilégios em sua expressão no cotidiano. Assim, esse jogo se encaixa como uma tecnologia cultural, por ter capacidade de influenciar e propagar determinados comportamentos culturais (SANTOS, 2012).

Os efeitos ocasionados com um discurso restritivo de vida da tecnologia cultural criam um sistema de exclusão. As normatividades inscritas no Jogo da Vida tem voz imperativa do que é certo ou errado de ser performado em sociedade. Como resultado dessa culpabilidade, é gerada uma violência simbólica para quem é transgressor das regras da normatividade (BOURDIEU, 2002). Através da pressão social, a culpa por desobedecer as normas da cultura ocidental se assemeIha com as relações de totem e tabu de Freud, pela norma atingir um patamar quase que sagrado, tendo que ser algo cultuado sem se duvidar de sua veracidade (FREUD, 2006). A violência simbólica funciona como um adestramento, em que no caso das normatividades regulam o processo de socialização esperado por quem detém o poder.

\section{AS MANIFESTAÇÕES DAS NORMATIVIDADES SOCIAIS NO JOGO DA VIDA}

Quando aplicada ao contexto do Jogo da Vida, as normatividades sociais aparecem como demonstrações de determinados poderes e padrões a serem enaltecidos. Começando pelos poderes, o primeiro a ser detectado quase que instan- 
taneamente é o econômico. Por meio do capital financeiro, é vitorioso no jogo aquele que detém mais dinheiro e que consegue demonstrar ao longo das partidas a capacidade de acumular bens materiais. A própria mecânica do jogo também auxilia nesse processo ao obrigar todos os jogadores em deter pelos menos um imóvel e algum veículo motorizado, geralmente um apartamento e um carro. Partindo para outra esfera, o poder religioso ganha destaque com a obrigatoriedade do jogador em parar e se casar no percurso de vida, juntamente com a impossibilidade de ter filhos antes do matrimônio; reforçando uma estrutura de pensamento com princípios judaico-cristãos.

Já o Poder simbólico, oferece subjetivamente hierarquias de importância social. Como exemplificação, é detectável práticas androcêntricas ao projetar o homem como agente principal das vivências do Jogo da Vida. O fato é comprovado por meio da narrativa, com profissões e adjetivos no masculino, e na estética, com predominância de homens ilustrados no tabuleiro. Reitera-se a desigualdade de gêneros ao mostrar as mulheres em patamar de submissão às ações masculinas de prestígios, uma que vez que as figuras femininas só aparecem no jogo como personagens secundários que enaltecem as realizações do homem.

Outras hierarquias, além da dominação masculina, se alinham com uma padronização de corpos e de performatividades esperadas de um cidadão exemplar que "vence na vida". A vivência considera válida é construída em torno do imaginário de um homem caucasiano, magro, heterossexual, bem sucedido financeiramente e com ambições de consumo em demasia. A problemática gerada com essa manifestação, está em quem não é privilegiado socialmente e se desalinha de quaisquer questões impostas por essas normatividades sociais. A violência simbólica, conceituada anteriormente, parece aqui por não constar no jogo representações de minorias sociais. Não há corpos negros, gordos, garotos afeminados, garotas masculinizadas, transgêneros, homossexuais 
ou qualquer outro indício de preocupação com a diversidade. Assim, as normatividades sociais homogeneízam as práticas do viver e o jogo reforça uma vida sem transgressões como a melhor e única forma propícia à felicidade e sucesso.

\section{CONSIDERAÇÕES FINAIS}

Após a explanação sobre as normatividades sociais e sua conexão com pensamentos de outros autores voltados ao campo teórico dos Estudos Culturais, é perceptível o detalhamento sobre o conceito utilizado como premissa na pesquisa a qual dá base a esse artigo. As normatividades sociais impactam especialmente no âmbito simbólico de poder, alterando nossas percepções e performatividades sociais. São elas que através de uma violência simbólica produzem uma sensação de culpabilidade ao que transgridem qualquer expectativa dentro de um estereótipo social moldado por instituições e indivíduos com poder.

A importância sobre o entendimento desse assunto e suas problematizações geradas no Jogo da Vida deram possibilidade para a prática projetual do trabalho de conclusão de curso a qual este artigo está vinculado. Nela, os questionamentos e análises diante do objeto de pesquisa serviram de base para um manual de como hackear o Jogo da Vida, ou seja, mudar sua estrutura narrativa, estética e mecânica a ponto de estabelecer as diretrizes para um futuro redesign do jogo. Essa rebelião diante das normas possibilitou vivências e corpos fora do padrão ocuparem espaços em vida e serem enaltecidos. Na estrutura física, corpos gordos e negros foram vangloriados a fim de fugir da lógica eurocêntrica da versão original do Jogo da Vida, além da inclusão de mais personagens femininas. O mesmo aconteceu com sexualidades e gêneros no jogo, fugindo de um padrão heteronormativo e propiciando questionamentos sobre o tema.

Com relação às etapas futuras, é esperado, através desses entendimento mais aprofundado sobre as normatividades sociais, gerar uma versão física do redesign do 
Jogo da Vida e procurar projetos e instituições que queiram incluir o novo jogo em suas atividades de ensino sobre questionamentos sociais.

\section{REFERÊNCIAS BIBLIOGRÁFICAS}

BOURDIEU, Pierre. O poder simbólico. Lisboa:

Difel, Rio de Janeiro: Bertrand, 1989.

BOURDIEU, Pierre. Questões de sociologia.

Rio de Janeiro: Marco Zero, 1983.

BOURDIEU, Pierre. A Dominação Masculina.

Tradução: Maria Helena Kuhner. Rio de

Janeiro: Bertrand Brasil, 2ª edição, 2002.

FOUCAULT, Michel. A ordem do discurso.

São Paulo: Ed. Loyola,1996.

FREUD, Sigmund. Totem e Tabu e Outros

Trabalhos. Rio de Janeiro: Imago, 2006.

KELLNER, Douglas. A Cultura de mídia - estudos

culturais: identidade e política entre o moderno

e o pós-moderno. Bauru, SP: EDUSC, 2001.

LEPORE, Jill. The Meaning of Life. The New

Yorker. 2007. Disponível em: <https://www.

newyorker.com/magazine/2007/05/21/the-

meaning-of-life> Acesso em: 23 nov. 2017.

LIMA, Tania Andrade. Cultura material: a dimensão concreta das relações sociais Boletim do Museu Paraense Emílio

Goeldi. Ciências Humanas, v. 6, n. 1, p. 11-23, jan.-abr. 2011.

MATHEUS, Pedro. A vida sem transgressões: 0 Jogo

da Vida como objeto cultural e sua propagação

de normatividades sociais. Universidade Federal

de Pelotas. Centro de Artes. Pelotas, 2018. 
SALEN, Katie; ZIMMERMAN, Eric. Regras

do jogo. Fundamentos do Design de Jogos.

Volume 1. São Paulo: Blucher, 2012.

SEFFNER, Fernando. Sigam-me os bons: apuros

e aflições nos enfren- tamentos ao regime de

heteronormatividade no espaço escolar. Educ.

Pesqui., São Paulo, v. 39, n. 1, p. 145-159, 2013.

SANTOS, A. P. Tecnologias sociais e culturais: reflexões sobre noções de tecnologia em políticas educacionais

e culturais. In: Ana Maria Dietrich; Artur Zimerman. (Org.).

Café com PP: novas abordagens de políticas públicas no

Brasil. 1ed.Santo André - SP: UFABC, 2012, v. 1, p. 88-104.

THE GAME of Life History - Invention of The Game

of Life. The Great Ideia Finder. 2006. Disponível

em: <http://www.ideafinder.com/history/ inventions/

gameoflife.htm> Acesso em: 23 nov. 2017.

VANZELLA, Lila Cristina Guimarães. 0 jogo da

vida: uso e significações. 2009. Tese (Doutorado

em Educação) - Faculdade de Educação,

Universidade de São Paulo, São Paulo, 2009. 